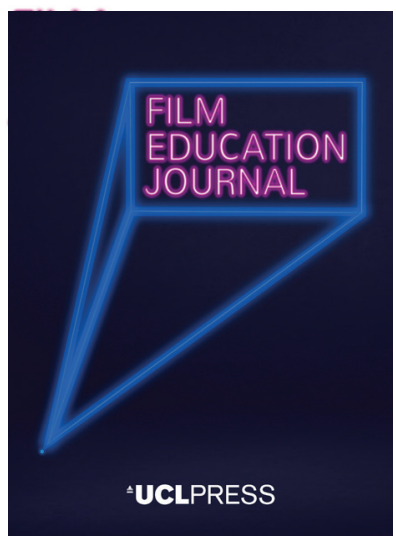

UCLPRESS

FILM EDUCATION JOURNAL

ISSN 2515-7086 (Online)

Journal homepage:

https://www.uclpress.co.uk/pages/film-education-journal

\title{
Decolonizing processes in film education
}

\author{
Jyoti Mistry (iD
}

\section{How to cite this article}

Mistry, J. (2021) 'Decolonizing processes in film education'. Film Education Journal, 4 (1), 1-13. https://doi.org/10.14324/FEJ.04.1.01

Submission date: 21 September 2020

Acceptance date: 13 November 2020

Publication date: 10 June 2021

\section{Peer review}

This article has been peer-reviewed through the journal's standard double-blind peer review, where both the reviewers and authors are anonymized during review.

\section{Copyright}

(C) 2021 Mistry. This is an open-access article distributed under the terms of the Creative Commons Attribution Licence (CC BY) 4.0 https://creativecommons.org/licenses/by/4.0/, which permits unrestricted use, distribution and reproduction in any medium, provided the original author and source are credited.

\section{Open access}

The Film Education Journal is a peer-reviewed open-access journal. 


\title{
Decolonizing processes in film education
}

\author{
Jyoti Mistry* - University of Gothenburg, Sweden
}

\begin{abstract}
This paper considers what decolonizing film education might mean through a series of research initiatives undertaken across different cultures which explore social media platforms for creating moving image sequences. The paper attends to three factors in the current climate of education: the accessibility of the medium, its immediacy in dissemination, and the democratizing effect that these conditions have had on the medium of film. Working with these three conditions in contemporary film education, the case studies described include workshops that aimed to shift the curriculum from film canons to proposing the introduction of concepts. Furthermore, elided histories are explored through site-specific projects that show how decolonial processes allow these histories to be reclaimed in film practice, and for marginal subjectivities to be made visible. Finally, the proposal of decolonial processes seeks to work with creating opportunities for social and historical visibilities. The proposition is to work with film(ed) evidence as material connected to broader social justice issues that are expressed through aesthetic forms closely associated with decolonial processes and described as decolonial aesthesis.
\end{abstract}

Keywords: decolonial processes, film aesthetics, social change, critical pedagogy, curriculum transformation

\section{Opening propositions}

The concept of decolonization has recently received increased attention across education institutions. Decolonization exposes the historical construction of power that has privileged Western epistemological structures, and reveals how knowledge in teaching-learning has reinforced historical oppressions and maintained the political certitude of these knowledge forms as more valid. This opening remark is a pithy generalization that requires elaboration to allow for a deeper, more nuanced understanding, and to connect its implication in the context of film education. More directly: What does 'decolonial' mean in the context of film education? How does the decolonial proposition enable reflexive shifts in film curriculum? What demand does it put on teachers and researchers, given that institutional frameworks often constrict knowledge transformations? Finally, with regard to the context of institutions, it is necessary to recognize that processes for decolonialization are not just about curriculum and the need to change the curriculum, but also about the attendant factors of student demographics, faculty expertise to include epistemologies that previously have not been recognized or included, and, significantly, the commitment from the institution to support these endeavours. These tiers of institutional transformations are central to decolonial processes in order to address the restructuring and reconfiguration of historical relations of power and knowledge. 


\section{A moment to attend to prefixes}

I am attentive to the historical temporalities of the colonial and postcolonial, but decolonial processes should not be understood in relation to these temporal-spatial configurations singularly. Instead, decolonial processes are not necessarily bound to the space of the colony in a literal sense, nor to the time before, during or after colonialism. In this context, the prefix 'de' invites a revised understanding of what it means to unlearn knowledges and structures of knowledge. As described by Ariella Aisha Azoulay (2019: 11):

Unlearning becomes a process of disengaging from the unquestioning use of political concepts - institutions such as citizen, archive, art, sovereignty, and human rights, as well as categories like the new and the neutral, all of which fuel the intrinsic imperial drive to 'progress', which conditions the way world history is organised, archived, articulated and represented.

This unlearning is central to decolonial propositions that challenge logocentric meanings, and the strategy invites critical questioning. It upturns binary oppositions and instead invites relational propositions. It is a way of looking at how knowledge is constructed, and how power structures that shape the historical and political conditions of knowledge have been normalized - power structures that are then institutionalized through dominant colonial systems or imperial powers. Decolonial processes reveal how knowledge is written from the perspective of colonial, white or Western references, and the institutional strategies that have fortified this knowledge and its aesthetic expressions and forms. This is particularly important for photography and film-making where archives and institutions have elided histories and/or politically erased peoples.

Notice that I am not advocating for the decolonial process to be a singular method or an approach that fixes the curriculum, but rather to be a process of openended awareness and engagement that will require constant historical and political discernment. It demands from us as educators and practitioners to be attuned to invisibilities of subjects in history, and to re-examine and re-search knowledge relations constantly.

In the spirit of this open-endedness, this paper does not aim to offer a prescriptive approach that may be adopted for all film education circumstances indiscriminately. Any political agenda of facilitating decolonizing processes in film education with the aim of creating an environment of critical pedagogy is continuously attentive to the historical, cultural and political specificities of its context. The case studies and experiments cited here have been part of a series of processes in teaching with film and in film. This distinction (between with and in film) is important, even though they are inextricably linked. There has been an institutional separation in film education between the practice of film-making on the one hand, and the theoretical and/or historical study of film (as in film/cinema studies) on the other hand. Understanding the distinction between with and in film allows these hitherto separate approaches to be brought closer together. Teaching with film further implies multiple disciplines that use films for analysis, films as illustrative and/or films to exemplify.

I am concerned with processes for decolonizing. As clarified above, there is no single method, approach or solution, but the proposition of decolonizing invites reflective, reflexive relations to structures of knowledge and ways to draw from 
multiple reference points. Simply put, decolonizing is a process of decentring singular knowledge paradigms, but with the approach of making visible those historical and political positions that have previously not been exposed. The process is about creating conducive environments in education to explore, first, what decolonizing means in particular historical and political contexts. Second, these processes lead to discoveries in how the curriculum needs to change, and how they transform film education in both vocational and research areas. Finally, film education has at its core vocational competencies (sometimes termed the 'six-pack' model) that ensure that students graduating will enter some form of (film) industry. In this paper, I focus on this in a less direct way, but I will suggest that processes for decolonizing have implications for the vocational curriculum as well as for the artistic and research aspects of film education. Educating Film-Makers by Duncan Petrie and Rod Stoneman (2014) offers well-documented historical contexts in the development of film schools in Britain, Europe and the USA which highlight the inherent contradictions in film education and teaching institutions.

Wherever possible, I have drawn from my experiments with curricula through various research projects and workshops, in the hope that these ideas have more concrete and tangible resonances through the examples. Inevitably, these examples are specific to the historical and political contexts in which the research has been conducted, and each research project was designed with a particular focus based on the said context. In maintaining the ethos of processes for decolonizing, epistemological and aesthetic shifts are re-evaluated, reconfigured and redesigned to counter dominant and prevailing references in film school curricula.

\section{Definitional differences}

I have not offered a survey of the field of decolonization, but have chosen to work strategically with two particular propositions of decolonization, to demonstrate how the term 'decolonization' has developed in different disciplines in the humanities. My intention is to work with these two parts of the definitional spectrum as they relate directly to the research projects (case studies) recounted here.

In the now seminal text 'Decolonialization is not a metaphor' by Eve Tuck and K. Wayne Yang (2012: 1), operational and implementation aspects of what decolonization implies are expressed with pointed cautions:

... decolonization makes possible a set of evasions, or 'settler moves to innocence', that problematically attempt to reconcile settler guilt and complicity, and rescue settler futurity. ... we analyze multiple settler moves towards innocence in order to forward 'an ethic of incommensurability' that recognizes what is distinct and what is sovereign for project(s) of decolonization in relation to human and civil rights based social justice projects.

Tuck and Yang (2012) focus on the insistence of land reparations and institutional roles in securing justice (as opposed to justice making). Their approach is a significant interjection towards addressing historical imbalances, and it has direct import later in this paper in the idea of film(ed) evidence - the proposition of which is to engage with image-making proliferation on social media as it impacts film education.

In contrast to the approach adopted by Tuck and Yang (2012), Walter Mignolo offers another entry by recognizing 'aestheSis' entanglements. His approach of defining decolonization in terms of artistic practices and its relation to knowledge is a 
necessary complement to the reparations approach sought by Tuck and Yang (2012). Interviewed by Gaztambide-Fernández (2014: 201), Mignolo says:

Decolonial aestheSis refers in general to any and every thinking and doing that is geared toward undoing a particular kind of aesthesis, of senses, that is the sensibility of the colonized subject. What decolonial artists want is not to create beautiful objects, installations, music, multimedia or whatever the possibilities are, but to create in order to decolonize sensibilities, to transform colonial aestheTics into decolonial aestheSis. In that regard, aestheTics is the image that reflects in the mirror of imperial/ colonial aesthetics in the Kantian tradition. Once you delink, you begin to create a world in which decolonial aestheSis has delinked from aesthetics, which has become aestheTics.

\section{Representation - enunciation}

The shift from aestheTics to aestheSis provides the necessary historical and political unlearning of cinematic conventions that continue to produce and reproduce products (content) that fortify the structures of capital and its representative forms of 'settler knowledge' (settler futurity produced through forms and practices that are representative). A decolonial proposition, and its potential in film education, is a way to delink, unlearn and create space for aesthetic practices (aestheSis) in films that are articulated from the position of the colonialized subject, and to recognize utterance instead of representation. Stuart Hall (1997: 28) writes:

Representation is the production of meaning through language. In representation, constructionists argue, we use signs, organized into languages of different kinds to communicate meaningfully with others. Languages can use signs to symbolize, stand for or reference objects, people and events in the so-called 'real' world ... Meaning is produced by the practice, the 'work', of representation. It is constructed through signifying - i.e. meaning-producing - practices.

This highlights the shift in emphasis, not to replace the significance of representation, but rather to recognize the political necessity of enabling utterance and/or enunciation as a direct mode of address in image making. In the interview with GaztambideFernández (2014: 198), Mignolo differentiates this from representation, which is defined through a modern epistemology that assumes that the world is outside the speaking subject:

... thinking decolonially (that is, thinking within the frame of the decolonial option) means to start from 'enunciation' and not from 'representation.' When you start from the enunciation and think decolonially, you shall run away from representation, for representation presupposes that there is a world out there that someone is representing. There is not a world that is represented, but a world that is constantly invented in the enunciation.

In order to make this relationship between representation and utterance concrete, I turn to an example drawn from the BRICS (Brazil, Russia, India, China and South Africa) research project which I conducted between 2017 and 2020. These five nations forged a geo-economic alliance in order to stimulate and strengthen trade relations. Expressed briefly, the aim of the research project was to focus on visual methodologies based on mutually agreed topics in each region, where students were given prompts 
to create filmed sequences. The insistence was on situatedness - in being attentive to the specifics of the reference points in each region, to its unique film culture, film history and sociopolitical concerns, and, most significantly, to the subjectivities of each of the participants.

I want to draw from the experience of working with my colleague Yu Ran from the Communication University of China, Beijing, who proposed that we work with the influence of social media platforms that use moving image sequences. We identified numerous platforms that rely on short, moving image sequences that convey ideas or experiences, then share-posted among followers on social media. I was inspired to collaborate with Yu Ran based on a paper he had given at the CILECT Congress (Centre International de Liaison des Ecoles de Cinéma et de Télévision - www.cilect.org) in 2018, 'The student is the industry' (Ran, 2018), in which he disclosed how students were involved in generating content for their own markets. In his case study, he described how one student had a following of a million viewers, and that it was not necessary for the student to aspire to a career in any film or broadcast industry because he had successfully created his own market and audience. In early 2019, Yu Ran and I, together with Nduka Mntambo from South Africa (University of the Witwatersrand, Film and Television, Johannesburg), ran a week-long research workshop with students from China and South Africa, with myself at the University of Gothenburg, Sweden, as the facilitator. The students overcame their linguistic differences and developed a cultural and political curiosity in a short time through the image sequences that they created and shared. Even though there were numerous challenges with the Chinese cyberwall - let alone managing three time zones across virtual platforms - we succeeded in generating 20 moving image sequences and final films from students using platforms such as Snapchat and TikTok. For the final films, students were asked to create film sequences in which they shared their aspirations from their own particular political and cultural vantage points.

A South African student, Shameelah Khan, made a short project To Remember Me as an immediate response to shootings at two mosques in New Zealand in March 2019 (which took place at the time of the research workshop). It is an intimate reaction to the news of the shootings and the social media coverage. Khan skilfully uses the mode of video diary and excerpts from the shooting rampage, intercut with video-game material, Donald Trump's Islamophobia speeches and social media feeds/responses to the events at the mosques. The film interrogates the construction of Islam in the media as a violent religion, in contrast with her experience of her religion (Islam) as one of love and forgiveness. In responding to the brief about the future and her aspirations, the film-maker voices her concern about the future of her own safety and the right to follow her religion. To Remember Me challenges the colonial construction of Islam, and describes an entangled relation to contemporary political cultural processes. As a young Muslim woman, Khan's utterances are 're-identification in relation to coloniality' (Mignolo, interviewed by Gaztambide-Fernández, 2014: 198). By drawing from media representations, Khan switches and subverts these representations through utterance in the video diary, and through enunciation in the image sequences created from multiple sources, she counters the 'hidden process of erasure, devaluation, and disavowing of certain human beings, ways of thinking, ways of living, and of doing in the world' (ibid.). With her film, Khan addresses 'coloniality as a process of inventing identifications' (ibid.), and these identifications of Islam; being a Muslim woman, the terror of Islam which has been constructed from a colonial or imperial position is brought into relief through multiple aesthetic references. The sum total produces an aestheSis in Mignolo's terms: 'then for identification to be decolonial it needs to be 
articulated as "des-identification"' (Mignolo, interviewed by Gaztambide-Fernández, 2014: 201). In this instance, the des-identification is created from the questions that the film-maker poses in the film, the political reckoning of how colonialism has produced Islam in its imagination, the ways in which Islam has been constructed in the media, and how these have impacted the construction of her subjectivity. The layers of subjectivity constructed through the negotiation of colonial identity formation of Islam in the West, and its immediate lived experiences in South Africa, form a vivid example of the negotiation between representation and enunciation through film language that exposes the entanglements of decolonial aesetheSis.

\section{From canon to concept}

Film education curricula are broadly predicated on drawing from a historical pantheon of film references and film history, couched primarily in terms of European and North American references. Jane Staiger (1985: Abstract) points out the complicated presuppositions in how canonical taxonomies have been developed, and in their organization: 'Canons and canon formation pose questions for the Academy: On what bases do we evaluate films? What are the politics of those judgments? ... [What] positions [are] taken regarding these questions, considering their economic and social contexts and the political implications of these positions'? What follows is a description of exploratory workshops that sought to reconceive film canons not as a way to replace historical canons, but to broaden the curriculum as part of a critical pedagogical approach. Film educators and practitioners across the regional network of European film schools (GEECT, Groupement Européen des Ecoles de Cinéma et de Télévision) in CILECT came together at the Netherlands Film Academy and Cologne Film School in January and March 2019 respectively, for twin conferences in which contemporary issues of diversity and inclusion in film education were foregrounded. The scope of the conferences covered several areas that addressed institutional factors of student recruitment, support for students from minority groups and how to address divergent lived experiences that impacted the teaching-learning environment.

Together with Mieke Bernink from the Netherlands Film Academy, I facilitated two workshops. The first workshop, in Amsterdam, called 'Canon exposed', unpacked the arguably unquestioned pantheon of films referenced in film education, which contributes to advancing specific ideological positions and particular aesthetic forms. The initial exercise was a forensic examination of film references used in our film programmes, and this generated many conversations and introspective reflections about our schools and how our own aesthetic benchmarking has been formed through our institutional training and personal aesthetic preferences. Furthermore, these references were often grounded in a cinema history to which most students could not relate any longer. Students brought their own references drawn from their generational experiences and exposure, but also from multiple sources, which included YouTube clips.

The second workshop, in Cologne, called 'Canon expanded', departed from the double-bind of defining canons (canons defined selectively using predetermined criteria to validate the taxonomy). The discussions in the workshop were dynamic because the exercises invited participants to shift their focus towards multiple cultural, political and geographical taxonomies. Using the invitation to shift from canon to concept, and by exploring strategies for collaborative ways of working with students on the design and content of the curriculum, the workshop enabled more imaginative connections between films and image sequences from different sources, rather than 
predetermination by genre or historical movements. Our approach to expanding the curriculum was inspired by bell hooks (1994: 39), who writes: 'Making the classroom a democratic setting where everyone feels a responsibility to contribute is a central goal of transformative pedagogy.'

In both workshops, Mieke Bernink and I endeavoured to include collective viewing experiences of short films as a way to reflect on how cultural and political backgrounds informed the interpretation of the aesthetic qualities and the content of the films. We further connected aesthetics to the political propositions that the films posed, and worked with the political and social concepts of the films rather than validating the received aesthetics in any of the canons or genres. It was significant that part of the discussion focused on how collective viewing experiences in film schools have been compromised in favour of individual viewing preparation on web platforms. We discussed at length the atmosphere generated by collective screenings, especially the experience of the cinema, which has radically changed over the last decade.

\section{Working with elided histories}

Another occasion for experimenting with decolonizing processes was made available in May 2019 at the University of Gothenburg in Sweden. Nina Mangalanayagam and I convened a highly expansive workshop-conference - titled 'Decolonising pedagogy: Exploring processes in image-making' - with the aim of using image-making practices to investigate the much-neglected subject of Swedish colonial history. We worked with a site-specific reference known as the French plot (Franska Tomten) near the city's water-edge, and students were provided with archival resources and historical material as the prompts, since few students were familiar with Sweden's colonial past. As we wrote in the introduction to the conference, 'The inception of the workshop drew from practices of image-making to create an environment where various cultural, geographic and disciplinary approaches were brought into conversation with each other.'

Lindiwe Dovey, from SOAS University of London, UK, conducted a workshop on sourcing and resourcing as one of the methods for broadening the curriculum. Setting the context for how subjectivity informs knowledge and practice, she drew from her own personal narrative and teaching experiences that necessitated shifting the reference points in teaching African cinema at SOAS. Her presentation, called 'Story of an African film', showed how student involvement created a platform for collaborative curriculum development, and how students could draw on their own experiences to advance their ideas about African cinema in contemporary political discussions. (The presentation has subsequently been published as 'On teaching and being taught: Reflections on decolonising pedagogy' (Dovey, 2020).)

Across the three days of the conference, we put practice at the centre by prioritizing aestheSis to generate an environment conducive to addressing 'approaches necessary for revising received certainties of western knowledge paradigms and included histories, multiple lived-experiences and subjectivities in the class that challenged dominant forms and their reference points' (Mignolo, interviewed by GaztambideFernández, 2014: 206). Again, it was through process and direct engagement with working inside the practice of film itself, as opposed to discourse on developing modes of representation, that we were able to come to a deeper understanding of how to create expansive frameworks for advancing teaching and learning, and for researching decolonial propositions. This process not only revealed structures of power and knowledge which had otherwise gone unquestioned with regard to Sweden's colonial past; by putting practice at the centre, the aesthetics of how to capture these 
experiences of elided histories also came to the fore. Simply put, how does one show forgotten colonial histories in film without reproducing colonial power relations? The accessibility of cameras and technology, and their immediacy, meant that within a short space of time (in this case, three days) several filmed projects were created that captured the discussions and political issues of what it means to explore decolonial strategies in film education through film itself.

\section{Product - process}

The film production process remains a highly regimented and hierarchical system that feeds the demand for endless content. The term film as product is arguably now less ubiquitous and, increasingly over the last several years, the term content drives the impulse in the vocational aspects of film education to cover the increasing plethora of dissemination and exhibition platforms, and the audiovisual content that they host. The term 'content' not only captures the end product, but also a shift in the singularity of auteur-driven films towards embracing the apparatus of production, which is writer-driven (the showrunner), and writer-director-driven on networks, with multiple viewing opportunities (as opposed to scheduled broadcast). This generalization is drawn from the influence of American models, but it has nonetheless penetrated most global markets. In the context of decolonizing film education, there are three significant convergences in a contemporary moment which contradict this version of the production process: first, the accessibility of the medium; second, its immediacy; and third, the democratizing potential of its dissemination and circulation. The impact of this convergence might revitalize film education to create a teachinglearning environment that is more conducive to experimentation with the politics and aesthetics of the medium. The learning experience inside tertiary education is vital for experimentation, trial and error, and experiencing failure. Paramount to the discussion are the processes of creating stories and characters, developing aesthetic and political enquiries, and exploring multiple visual reference points that move beyond what has been canonized over several decades of film education. The question of what film education offers in the context of institutions remains fraught, however, especially with escalating tuition costs and the insistence that film-making invites autodidacticism.

On the notion of accessibility, the technology and software, and information about mastering the technical craft elements of the medium, are obtainable through multiple sources. Basic editing software is often built into computer packages, and access to, and the affordability of, recording equipment through consumer cameras and mobile phones has become easier over the last three decades. Certainly, the history of avant-garde and experimental cinema proves that consumer cameras (from $8 \mathrm{~mm}$ film to video cameras) are vital to the history of non-commercial film-making. From script development to finished film, the film workflow can now be achieved more inexpensively, and more accessibly to non-specialists, than ever before.

Extensive tutorials on internet platforms implicitly guarantee success in wellorganized modules, often tutored by seasoned professionals in the field (for example, in scriptwriting and directing). Access to technology and harnessing the necessary skills are just part of accessibility. Another arm of the technical and tutorial access is the presence of the 'master'. No longer is it just the technology, the software and the accompanying tutorials; film schools also pride themselves on the role of 'masters' in their film education programmes (award-winning writers, directors, cinematographers and so on). These gurus, experts and masters, and the idea of their idiosyncratic genius, are also accessible and immediately available. Consider the barrage of masterclass 
advertising: the master is available at 90 euros a class or 180 euros for an annual subscription. Diversity is also addressed - from Martin Scorsese to Mira Nair, Shonda Rhimes to Aaron Sorkin, Ron Howard, Spike Lee and David Lynch to Werner Herzog, Samuel L. Jackson, Helen Mirren and Natalie Portman - and, of course, the promise on these platforms is that they continue making more masters accessible, thus exhibiting self-reflective awareness of race and gender, and film formats and film genres to attract all students without exclusion.

In addition to greater accessibility, technological affordances have created conditions of immediacy. Immediacy is facilitated by compressed workflows or multiple flows simultaneously, and in some instances by being able to produce so-called professional-looking images and sound from literally the device in your pocket. Immediacy is about being able to respond promptly, if not immediately, to generate films that are reactive to the situation - an immediacy that reacts to the world in its moment, and shares that reaction with others. The films are not just of the zeitgeist but in the zeitgeist. Immediacy is one of the core ideas in the processes for decolonizing the curriculum that relates both to film(ed) evidence and to its democratizing potential.

My first foray with the value of using accessibility and immediacy in film education was in South Africa during the Rhodes Must Fall protests in March 2015. Students documented the protests against the monuments to colonial mining magnate Cecil John Rhodes with their phone cameras. Evolving from these protests, the Fees Must Fall movement in October 2015 found increased numbers of students filming events and their experiences, and covering activities from various vantage points. At the time, I responded to the events by including a focus on how monuments might be used to render place and contested histories, and how languages form an inherent part of identity, and further explored the role of subjectivity in film practice. This accessibility and immediacy were the prompts to use film(ed) evidence in a more direct way in film education.

Finally, accessibility and immediacy have some attendant processes for democratizing through the medium of film. The technology has created a space for more democratic access and circulation of filmed image sequences, and so film education should demand a revitalized approach to how (the methods we use to teach) and for whom we teach (not just the students, but also their audiences). This has meant that the term 'content' has derived greater currency - and currency is the appropriate term, alluding to the monetization of content on numerous platforms, and how students also monetize the content they generate. The aspiration for film festival prestige, theatrical film release with box office, broadcast on television or securing the next big series as showrunner can, for young graduates, be immediate among the opportunities in an organized industry; these are among several professional and creative competencies that they may pursue after graduation. In a world where content moves not only on big screens, but also on small screens and screens everywhere, however, the monetization of content allows for individual entrepreneurship outside those routes on account of the immediacy, accessibility and democratizing potential of film in the present moment.

To return to the example of the BRICS research project To Remember Me, such a project would not have been possible without access to social media images and the immediacy of the film medium, nor without its proliferation on social media. Moreover, the workshop-conference 'Decolonising pedagogy: Exploring processes in imagemaking' was able to put practice at its centre because the feedback and sessions, which were delivered as image sequences, could be created in a short time precisely 
because of the immediacy of the medium and access to content from the internet to develop the responses.

\section{Film(ed) evidence}

In this section, I draw the connection of accessibility and immediacy closer to the proposition of democratizing processes and the implications for thinking about how films serve increasingly as evidence created in the public domain. The implications of film(ed) evidence in contemporary film education are central to how we might address contemporary political urgencies as part of the processes for decolonizing. Recall that decolonizing processes lay bare the political structures of power that make particular ethical and aesthetic relations transparent. Thus, knowledge is exposed as coded through this relationship, and aestheSis forms are exploratory ways to expose the experiences and enunciations that come to be expressed (rather than only represented) by colonized or oppressed subjects. The aim is to make visible these experiences on their own terms, not as representation, but to facilitate enunciation forms that can delink from the colonial or imperial modes of expression. How do we create a context for this in film education?

Consider the initial potential of this idea first expressed in one of the most seminal films in European cinema.

1966: Michelangelo Antonioni's Blow-Up has as its centrepiece the connections between film, photography and the 'optical unconscious', as Walter Benjamin described it: 'The camera reveals aspects of reality that register in our senses but never quite get processed consciously' (cited in Prouty, 2009). Thomas, the photographer, is witness to a murder that he does not see with his naked eye, but through a lens. He develops an obsession with discovering the meaning of a sequence of events in a park, and, in an attempt to understand what he thinks he has seen, blows up his photographs as forensic evidence of a murder - not for a trial, but to satiate his own curiosity. Forgacs (2017) argues of Blow-Up: 'There is also an allusion to the way the various amateur films and photographs recording John F. Kennedy's assassination in November 1963 had been blown up, slowed down, and connected in the official investigations of the Warren Commission (1963-4).'

17 March 1991: An amateur video recording made by George Holliday from his nearby balcony captures the violent beating of Rodney King by Los Angeles police officers. Holliday subsequently sends the videotape to the local television station KTLA. The images from the Rodney King beating are blown up and slowed down, and their distortions become part of a trial in which the police officers are acquitted: 'BlowUp is about photographic images and the elusiveness of the real' (Forgacs, 2017).

1994: Bill Nichols (1994: ix) writes about documentary theory in his well-received book Blurred Boundaries:

Inevitably, the distinction between fact and fiction blurs when claims about reality get cast as narratives. We enter a zone where the world put before us lies between one not of our own - and one that very well might be, between the world we may recognize as a fragment of our own and one that may seem fabricated from such fragments between the indexical (authentic) signs of reality and cinematic (invented) interpretations of this reality. 
Nichols (1994: $\mathrm{x}$ ) further poses the question:

In what ways does the videotape of the beating of Rodney King by officers of the Los Angeles Police Department adopt a form that appears to guarantee a truth? And does it? ... What blurred boundaries are up for grabs when we approach questions of truth, history, meaning and values in this area of visual documentation and textual interpretation?

17 July 2014: Footage of the killing of Eric Garner by New York Police Department officers is public.

25 May 2020: Footage of the killing of George Floyd by Minneapolis Police Department officers is public.

1 June 2020: Spike Lee creates a short film, 3 Brothers, which he posts on Twitter. Lee uses material from his film Do the Right Thing (1989), in which the character Radio Raheem is killed by New York police officers, intercut with the footage of the murders of Eric Garner and George Floyd.

The proposition of film(ed) evidence aims to investigate through film the status of filmed material that captures institutional violence: police brutality, social and civil unrest, and political inequality in times of accessibility and immediacy. Does this convergence not raise the question of the status of the 'optical unconscious' (Benjamin, cited in Prouty, 2009)? Is the concept of the optical unconscious still a legitimate way of thinking about a disconnect to reality? And what is the status of Nichols's (1994: $x$ ) proposition that the footage might not guarantee a truth? Whom does the optical unconscious serve in its lack of connection to reality?

Recall: the optical unconscious through the lens reveals something that our senses perceive, and our consciousness does not grasp. This is a valuable disjunct to address the status of the image and the filmed sequence - the fragment that may be both indexical and/or cinematic, which are no longer exclusive of each other but are collapsed in this moment of access and immediacy which demands that our consciousness takes full grasp of the reality to which it is exposed. Spike Lee's intercutting of the cinematic with the indexical film(ed) evidence makes this vivid, and forces a radical re-examination of the propositions of the relationships between the lens and the real. Moreover, it exposes the divergent, incommensurable realties and imaginations of white and black people, colonizer and colonized peoples, indigenous peoples and settlers, and it requires that we find ways to approach these ideas in film education. This would be yet another example of how decolonizing processes might work in film education.

\section{The political urgency for change}

I would like to cite a poignant anecdote that Claudia Rankine shared in an interview with David L. Ulin (2016) in the Paris Review:

One man said he was moved by a reading I gave and wanted to do something to help me. I said I personally had a privileged life, which I do, and that I didn't need his help.

What I needed was for him - this was a white gentleman - to understand the urgency of the situation for him and to help himself in an America that was so racially divided. 
It wasn't about him coming from his own position of privilege - of white privilege - to take black people on as a burden, but rather to understand that we are all part of the same broken structures. He said, I can take what you're saying, but you're going to shut down everybody else in this audience. And all of a sudden, I was like, What? I thought you wanted to help me! To remove him from the role of 'white saviour' was to attack him in his own imagination.

The work in education is to embrace these challenges, and to recognize that we are at a critical political and historical boiling point when it is no longer possible to assume a singular narrative or to remain confident in monolithic structures of knowledge. Rather, these are woven and entwined in the land, trauma and narratives of those groups whose enunciations have not been heard, let alone understood. Walter Mignolo, interviewed by Gaztambide-Fernández (2014: 203), observes that 'decolonial thinkers and doers have to work in the entanglement and differential of power'. In this sense, the toil is of working through these entanglements and, in the words of bell hooks (1994: 39), 'the willingness to approach teaching from a standpoint that includes awareness of race, sex and class'. Learning and teaching are fuelled by curiosity, willingness to experiment, openness to the experiences of others, and recognition of and respect for differences. This openness must come from students and teachers alike, but it demands resilience and bravery to endure the complexities that we discover.

\section{Notes on the contributor}

Jyoti Mistry is Professor of Film at HDK-Valand, University of Gothenburg, Sweden. She has made critically acclaimed films in multiple genres and has published on artistic research in film. In 2016, she was recipient of the CILECT (Association of International Film Schools) Teaching Award in recognition of innovation in practices in film research and pedagogy. She is editor-in-chief of PARSE (Platform for Artistic Research in Sweden), and her current research project is on indigenous histories in Sweden.

\section{Filmography}

3 Brothers: Radio Raheem, Eric Garner and George Floyd (US 2020, Spike Lee) Blow-Up (GB/IT 1966, Michelangelo Antonioni)

Do the Right Thing (US 1989, Spike Lee)

\section{References}

Azoulay, A.A. (2019) Potential History: Unlearning imperialism. London: Verso.

Dovey, L. (2020) 'On teaching and being taught: Reflections on decolonising pedagogy'. PARSE Journal: Intersections, 11. Accessed 16 February 2021. https://parsejournal.com/article/onteaching-and-being-taught/.

Forgacs, D. (2017) 'Blow-Up: In the details', The Criterion Collection Essays, 28 March. Accessed 16 February 2021. https://criterion.com/current/posts/4478-blow-up-in-the-details.

Gaztambide-Fernández, R. (2014) 'Decolonial options and artistic/aestheSic entanglements: An interview with Walter Mignolo'. Decolonization: Indigeneity, Education and Society, 3 (1), 196-212. Accessed 16 February 2021. https://jps.library.utoronto.ca/index.php/des/article/ view/21310.

Hall, S. (1997) Representation: Cultural representations and signifying practices. London: Open University, Sage.

hooks, b. (1994) Teaching to Transgress: Education as a practice of freedom. New York: Routledge. 
Nichols, B. (1994) Blurred Boundaries: Questions of meaning in contemporary culture. Bloomington: Indiana University Press.

Petrie, D. and Stoneman, R. (2014) Educating Film-Makers: Past, present and future. Bristol: Intellect.

Prouty, R. (2009) 'The optical unconscious'. One-Way Street: Aesthetics and politics, blog. 16 October. Accessed 16 February 2021. https://onewaystreet.typepad.com/one_way_ street/2009/10/the-optical-unconscious.html.

Ran, Y. (2018) 'The student is the industry'. Paper presented at the CILECT Congress, Mumbai, 13 November.

Staiger, J. (1985) 'The politics of film canons'. Cinema Journal, 24 (3), 4-23. https://doi.org/10.2307/1225428.

Tuck, E. and Yang, K.W. (2012) 'Decolonization is not a metaphor'. Decolonization: Indigeneity, education and society, 1 (1), 1-40. Accessed 16 February 2021. https://jps.library.utoronto.ca/ index.php/des/article/view/18630/15554.

Ulin, D.L. (2016) 'Claudia Rankine, the art of poetry no. 102'. Paris Review, 219. Accessed 16 February 2021. www.theparisreview.org/interviews/6905/the-art-of-poetry-no-102claudia-rankine. 